\title{
Energy Intensity of Water End-Uses
}

\author{
Afreen Siddiqi • Sarah Fletcher
}

Published online: 10 February 2015

(C) Springer International Publishing AG 2015

\begin{abstract}
Water end-use, in buildings, industrial facilities, and farms, often has the highest energy intensity. This review highlights key findings on energy intensity of water end-use in urban and agricultural sectors. In the domestic sector, energy used for water heating constitutes 14-25\% of total energy use in US households. Heat pumps for energy recovery from hot grey water in residential buildings, and micro-turbines operating from grey water in tall buildings, are being increasingly explored. In agriculture, groundwater pumping consumes most of the on-farm energy, and water-efficient pressurized delivery systems have higher energy consumption. Rainwater harvesting systems are being deployed in many regions. The energy intensity range for residential rainwater harvesting has been reported to be $0.6-5.3 \mathrm{kWh} / \mathrm{m}^{3}$ in Australia. However, with improved pump efficiency, the intensity can be lowered to $1.5 \mathrm{kWh} / \mathrm{m}^{3}$, which would be less than other nonconventional sources such as seawater desalination or indirect potable reuse.
\end{abstract}

Keywords Water end-use · Energy intensity · Water-energy nexus $\cdot$ Urban water $\cdot$ Hot water energy use $\cdot$ Rainwater harvesting · Water use efficiency · Energy efficiency · Irrigation · Groundwater pumping · Water sector GHG emissions $\cdot$ Life cycle analysis

This article is part of the Topical Collection on Energy-Water Nexus

A. Siddiqi $(\bowtie) \cdot$ S. Fletcher

Engineering Systems Division, Massachusetts Institute of

Technology, 77 Massachusetts Ave, Cambridge, MA 02139, USA

e-mail: siddiqi@mit.edu

S. Fletcher

e-mail: sfletch@mit.edu

\section{Introduction}

The linkages between energy and water have been extensively investigated; however, some aspects of energy use in the water sector are often excluded due to differences in definition of boundaries within the water sector. In particular, the end-use segment (wherein water is used for various purposes within buildings, residences, industrial facilities, and farms) is frequently overlooked since this process occurs outside the water industry $[1 \bullet \cdot$ and, often, state and federal jurisdictions [2]. However, the end-use segment within the cycle of abstraction, conveyance, treatment, distribution, end-use, and disposal (see Fig. 1) has been identified to have the highest energy intensity in many regions $[3-5,6 \bullet \bullet, 7 \bullet]$. Many researchers have worked to identify and quantify the energy intensity of water end-uses (energy consumed per unit of water), and in this study we conduct a review of this research over the last 3 years, with a focus on the residential and agricultural sectors.

Water end-use in urban areas is the type of usage that is measured via metered water consumption at the building, facility, or lot scale in a city. For end-use, energy is required for on-site pumping (e.g. in the case of high-rise buildings) and heating (to obtain a hot water supply in the building). In residential water use applications, energy is used in appliances such as clothes washers and dishwashers. In landscaping applications, some additional pumps and electrical control equipment (motors and valves) may be used that add to the energy consumption. For buildings with on-site wastewater recycling units, energy is consumed in running the units to treat and pump the recycled water. Industrial facilities use water in various operations and have associated energy requirements, typically in terms of pumping, pressurization, heating, cooling, and treatment of water. 


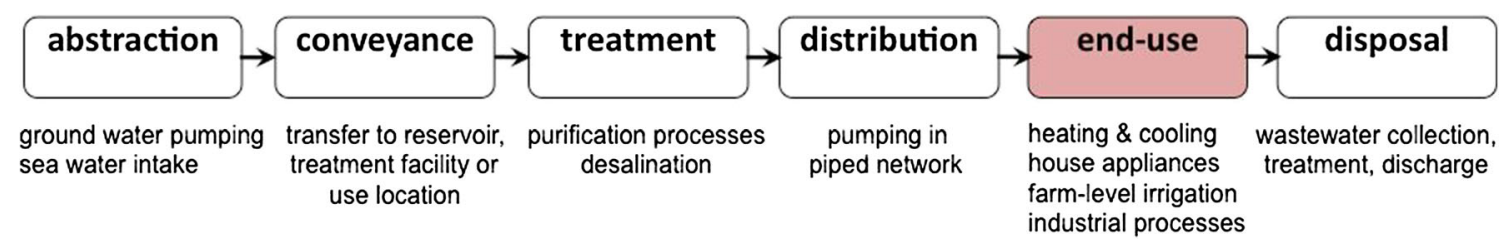

Fig. 1 Key segments of the water use cycle. The end-use is the most energy intensive in many regions

Agriculture has the highest water consumption of any sector, including the domestic and industrial sectors, and the energy consumed for pumping irrigation water constitutes a large fraction of total energy use in several agrarian regions $[8 \bullet \bullet, 9]$. Energy use for pumping groundwater depends on the geology, pumping equipment technology, and volume of abstracted water. Energy is also used in pressurized irrigation systems such as drip and sprinkler systems.

In the following sections of this paper, we present a review of studies conducted on energy intensity of water end-use in urban and agricultural sectors published during 2011-2014. We summarize their regional and topical focus, and present reported data of energy intensity in various end-uses. We also summarize methods employed for analyzing and quantifying the energy intensity and discuss existing knowledge gaps in this area.

\section{Trends in Energy Intensity of Water End-Use Studies}

In order to obtain an overview of key trends in publications on energy intensity of water end-use, we compiled data for English language journal articles in the Web of Science (Science Citation Index and Social Science Citation Index) during the
2011-2014 period. We conducted a topic search of the terms 'water', 'energy', and 'end-use'. This search provided publications that have these terms in their title, abstract, or keywords list. We tabulated the results by research area and by country of authors. Research areas are defined in the Web of Science database to categorize publications according to a particular discipline (details of which can be found on the Web of Science website [10]). The country of authors was determined by the address provided by the authors of the papers. However, it should be noted that the address of the author does not necessarily correspond with the region analyzed in the paper. For instance, in several papers, authors based in the USA investigated other regions, including Mexico, Pakistan, and others.

Figure 2 summarizes the results (obtained in November 2014). The top research areas of publications were energy fuels, engineering, environmental sciences, and construction building technology. The literature is dominated by a focus on energy (it is interesting to note that environmental science and ecology rank third and water resources ranks fifth in number of total journal articles).

We also find that USA, Australia, Canada, and England are the leading countries where researchers have published work on this topic. Note that we combined several small shares of
Fig. 2 Research areas and country of authors of journal articles published between 2011 and 2014 with the terms 'water', 'energy', and 'end-use' in the paper's title, abstract, or keywords

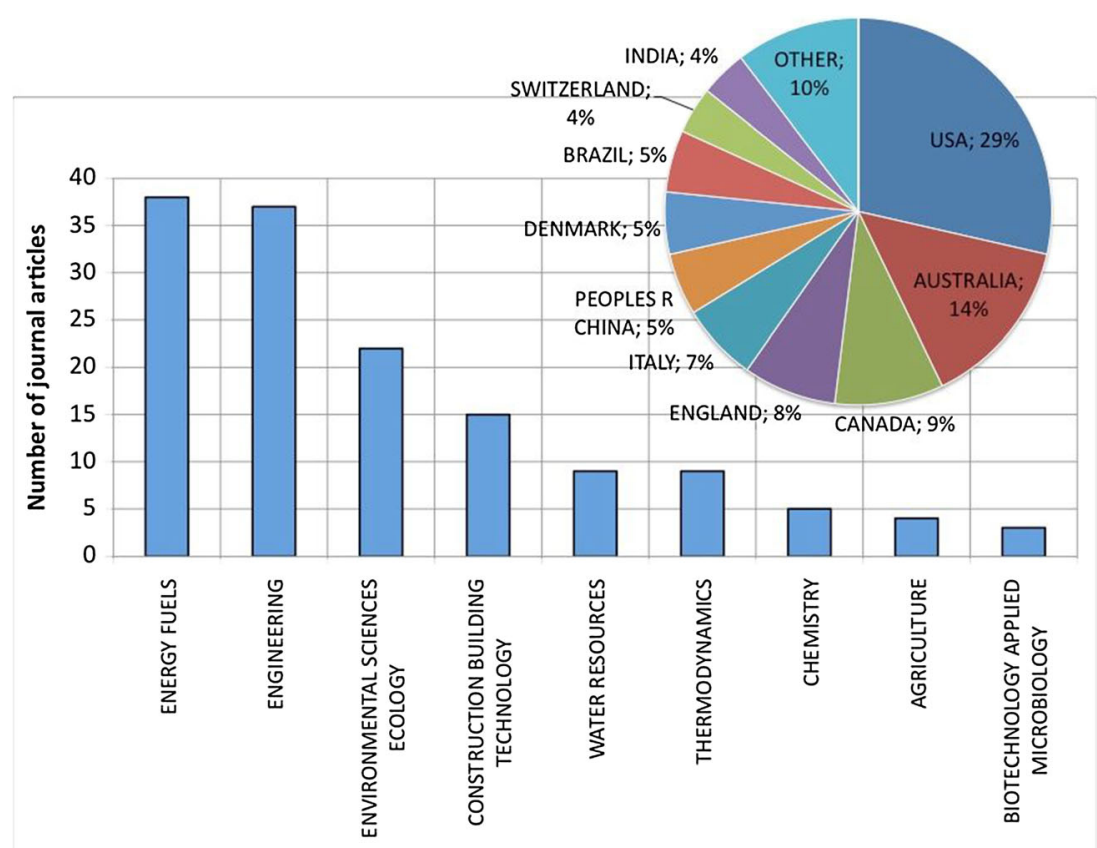


countries into the 'other' category in the pie chart to improve clarity of the figure. It is interesting to note that, from a regional perspective, the research has been driven by local resource scarcity. The Australian work is more from a water security perspective, while in the USA and many other countries, it has largely been motivated from an energy security perspective [11]. A number of studies in countries such as India and China focus on the agricultural sector, where energy use in groundwater pumping constitutes a large fraction of total energy use in some states and provinces.

The papers reviewed in this study were primarily of three types: (1) reports of measurement and field-data collection; (2) theoretical analysis, modeling, and estimation; and (3) review papers that compiled and discussed data reported elsewhere. The first type of papers employed instrumentation and data collection methods, including the use of smart meters, data acquisition systems, and analytical software for monitoring and field-data collection (such as that reported in Talebpour et al. [12•]) and data collection through field interviews and surveys $[13 \bullet, 14 \bullet]$. The second type included a range of methodologies (depending on the focus of the paper) that included methods that are both widely known and used as well as custom tools and new methods developed by the authors. Some of the known methodologies included life cycle analysis [15•], probabilistic modeling, Monte Carlo simulations, and regressions [16•]. Some new tools included the Water-Energy Nexus (WEN) tool [5] and quantitative modeling approaches [9, 17-19]. The third type presented compiled data reported elsewhere and discussed research and policy implications such as in Rothausen and Conway [1••], Plappally and Lienhard [6••], Nair et al. [20], Grant et al. [21••], and others.

\section{Energy Consumption in Residential Water Use}

The energy intensity varies with the type of source and supply architecture of the water system, the local climate and temperature conditions, and behavioral factors. It has been reported that end-use energy requirements associated with municipal, industrial, and self-supplied sectors (such as agriculture, mining, and power plants) represent $5 \%$ or more of the national energy consumption in the USA [22], and energy consumed for household water use in Beijing is $\sim 1 \%$ of the city's total energy consumption [17]. A number of studies have sought to compile previous work and report on energy intensity of residential water end-uses. One of the most comprehensive reviews is from Plappally and Lienhard [6••]. Their work, a compilation of data from a number of sources, provides a detailed report of energy use in water heating, appliances (such as dishwashers and clothes washers), and cooking. Their study finds that the range of energy intensity for hot water heating varies significantly, with estimates ranging from 2.7 to $73 \mathrm{kWh} / \mathrm{m}^{3}$. Several factors account for this large range.
Differences in building types such as homes, apartment buildings, offices, and hospitals, and the external temperature (local weather conditions) influence how much energy is used. Furthermore, individual appliances vary significantly. Electric water heaters have higher end-use efficiencies than natural gas water heaters, but significant electrical losses make the primary energy use greater. The same conclusions are found in the report by the Massachusetts Institute of Technology, USA [23], and it was determined that, over the full fuel cycle, natural gas water heaters are about twice as efficient. It should be noted that the amount of water heated in residences varies significantly with geography, so the energy intensity of the appliance does not capture the full picture of the energy efficiency of water use. Overall, water heating accounts for $97 \%$ of energy use for water end-uses in households in Australia [20], and it has been reported that water heating accounts for $75 \%$ of the residential sector's direct water-related energy in the USA [24]. On a national scale, 14-25\% of energy supplied to residences is used for heating water in the USA [6••]. Table 1 summarizes reported data of energy intensity for residential water heating and other water-related end-uses.

Abdallah and Rosenberg [16•] analyzed a large water-use dataset of 11 cities in the USA and determined that water and energy distributions among households are skewed, with the largest $12 \%$ of the users consuming $21 \%$ and $24 \%$ of water and energy, respectively. Their results showed that water heater set point temperature, intake temperature, heater efficiency, and shower hot water fraction were among the factors with the highest relative effect on household energy use.

Table 1 Energy-intensity ranges reported for domestic and agricultural end-use

\begin{tabular}{|c|c|c|}
\hline $\begin{array}{l}\text { Energy } \\
\text { intensity }\end{array}$ & Notes & Reference \\
\hline \multicolumn{3}{|c|}{ Residential end-use $\left(\mathrm{kWh} / \mathrm{m}^{3}\right)$} \\
\hline $0-54$ & Residential water heating & {$[1 \bullet \bullet]$} \\
\hline 35 & Natural gas water heaters & {$[6 \bullet \bullet]$} \\
\hline 73 & Electric water heaters & {$[6 \bullet \bullet]$} \\
\hline $47-50$ & $\begin{array}{l}\text { Hot water residential use in six Australian } \\
\text { cities }\end{array}$ & {$[6 \bullet \bullet]$} \\
\hline 53 & Hot water domestic use in Finland & {$[6 \bullet \bullet]$} \\
\hline $30-80$ & $\begin{array}{l}\text { Hot water in apartment buildings in } \\
\text { Estonia }\end{array}$ & {$[6 \bullet \bullet]$} \\
\hline \multicolumn{3}{|c|}{ Rainwater harvesting $\left(\mathrm{kWh} / \mathrm{m}^{3}\right)$} \\
\hline 4.01 & $\begin{array}{l}\text { Specific energy for centralized communal } \\
\text { rainwater supply }\end{array}$ & {$[25]$} \\
\hline $0.83-2.26$ & $\begin{array}{l}\text { Single residence rainwater harvesting } \\
\text { system }\end{array}$ & {$[12 \bullet]$} \\
\hline $0.6-5.3$ & Household rainwater harvesting system & {$[26]$} \\
\hline \multicolumn{3}{|c|}{ Irrigation $(\mathrm{kWh} / \mathrm{ha})$} \\
\hline $455-1901$ & $\begin{array}{l}\text { Pressurized irrigation system in ten } \\
\text { representative districts in Spain }\end{array}$ & {$[27]$} \\
\hline $833-36,101$ & Range of energy use for irrigation & {$[1 \bullet \bullet]$} \\
\hline
\end{tabular}


While the efficiency of appliances and technology are key factors in reducing the energy intensity of water end-uses, user behavior is likely the most important factor. The results in Abdallah and Rosenberg [16.] and other studies before it $[13 \bullet, 21 \bullet \bullet, 28]$ have highlighted the importance of end-user behavior on impacting both the amount of water used and the energy consumed with water use. The water heater set point temperature and shower hot water fraction are factors controlled by the human end-users, and efforts to reduce energy intensity of water end-use need to include measures of influencing end-user choices. The cost of energy for water end-use is borne directly by the users [29], unlike other segments where water utilities or other agencies pay for the energy costs. These cost implications should be highlighted to influence end-user behavior and expand conservation efforts.

A number of studies, mostly based in Australia, have focused on assessing the energy intensity of alternative water systems and comparisons with conventional water supply in residences. The increasing freshwater scarcity in Australia has driven state and local governments to mandate internally plumbed rainwater tanks [12•]. There is an increasing shift to decentralized water sources (that include rooftop rainwater harvesting, water recycling, and reuse, etc.) in the region. Researchers have noted that the net impact on energy use is neither considered nor fully investigated in designing and implementing policies that encourage users to use these sources. There is also a gap in understanding the environmental implications of decentralized water supply and use systems [20].

The rainwater harvesting systems are alternatives to conventional reticulated water supply, and are installed at individual residences to supply water for specific non-potable enduses such as toilet flushing and clothes washing. The reported literature has used a combination of modeling and empirical observation to estimate the energy intensity of rainwater harvesting systems. Most papers reported a range for the energy intensities, between 0.6 and $5.3 \mathrm{kWh} / \mathrm{m}^{3}$ (see Table 1). Some present small case studies on a few in-home systems using smart meters and other new technologies that allow for detailed data collection of water use events and associated energy use in residences $[12 \cdot, 25,26])$. The authors note that efforts to match more appropriately sized pumps with each system could lower the energy intensity. Vieira et al. [30•] have provided a detailed review of the energy intensity of rainwater-harvesting systems. They note that the median energy intensity of theoretical studies was $0.2 \mathrm{kWh} / \mathrm{m}^{3}$, which was considerably lower than the $1.4 \mathrm{kWh} / \mathrm{m}^{3}$ reported in empirical studies. The lower theoretical estimates could be due to lack of full accounting of energy losses and inefficiencies. Tjandraatmadja et al. [26] note that rainwater harvesting has a much higher energy intensity than conventional reticulated supplies for the same uses in Australia $\left(0.21\right.$ and $0.67 \mathrm{kWh} / \mathrm{m}^{3}$ in Melbourne and Brisbane, respectively). More data collection is needed as these systems become both more abundant and more efficient. They also note that with improved pump matching with end-use needs (that vary for washing machines, dishwashers, faucets, and toilets), the energy intensity can be reduced to $<1.5 \mathrm{kWh} / \mathrm{m}^{3}$, which would make rainwater harvesting more energy efficient than other non-conventional sources such as seawater desalination $\left(3.6 \mathrm{kWh} / \mathrm{m}^{3}\right)$ or indirect potable reuse $\left(2.8-3.8 \mathrm{kWh} / \mathrm{m}^{3}\right)$.

Most of the studies focused on a single residence scale, but rainwater supply on a larger scale is also being assessed. Cook et al. [25] report on the communal use of rainwater-harvesting systems that can supply potable water to a small urban development, albiet at a higher energy usage (estimated at $4.01 \mathrm{kWh} / \mathrm{m}^{3}$ ) than a large centralized water supply. Their analysis shows that rainwater use can be expanded beyond the single household to larger community-level use in certain regional contexts.

\section{Energy Intensity in Agricultural End-Uses}

Water-energy linkage studies across different water sectors in many developing countries predominantly focus on energy use in the provision of irrigation water [20]. The energy consumption in water-related end-use in agriculture (that occurs at the farm level) is primarily associated with on-farm groundwater pumping and energy used in pressurized water distribution and application systems at the field level.

Facing increasing competition for water, many regions have started to shift to pressurized irrigation systems that are more water efficient [18]. The water efficiency can be increased by replacing gravity-fed systems such as border check and furrow with pressurized center pivot and drip systems that can provide significant reductions in water application on the field scale. However, these water-efficient systems are more energy intensive. The overall farm-level energy intensity of water use depends on both the irrigation water source and the field application technology. For farms using pumped groundwater for irrigation, water-efficient application technologies (such as drip and sprinklers) allow for less pumping and for overall energy savings at the farm level. However, farms receiving surface water for irrigation can experience an increase in energy consumption with the use of pressurized irrigation systems [31].

An approach that can mitigate this trade-off is the reuse of grey water in irrigation systems. Matos et al. [32] find that grey water decentralized reuse systems consumed between 11.8 and $37.5 \%$ of the energy of a wastewater centralized reuse system.

In many parts of the world, there is an increasing trend to replace open channels that distribute irrigation water with pressurized pipes in order to reduce water losses due to evaporation and seepage. Some recent papers describe methods to optimize pressurized irrigation networks to minimize the energy consumption in irrigation water distribution in Spain [19, 
33]. Abadia et al. [34] applied these methods to a real system in Spain and achieved a $34 \%$ reduction in energy consumption.

The water and energy trade-offs at farm-level production are ultimately connected with agricultural output and economic benefit on local and regional scales. A number of studies focusing on different parts of the world have quantified energy use in irrigation and water and energy productivity in irrigated agriculture.

Hafeez et al. [35] conducted a study to analyze water productivity with water reuse on five different spatial scales in a rice-dominated irrigated region in central Luzon in the Philippines. The water reuse was through groundwater pumping in downstream regions of the area under study, where water reaches the area through percolation from upstream irrigation. They found that water productivity $\left(\mathrm{US} \$ / \mathrm{m}^{3}\right)$ with water reuse was higher than without water reuse; however, total energy inputs for water reuse were $28 \%$ higher than energy inputs without water reuse. Thus, while reuse contributed to increasing water productivity, it also increased energy use (due to pumping), indicating a trade-off between yield and energy use.

Siddiqi and Wescoat [9] found a similar trend in the Punjab province of Pakistan [9]. They used annual production, agricultural machinery census data, and water pumping estimates and estimated that, while there was a $31 \%$ increase in crop production between 1995 and 2010, the direct on-farm energy intensity (mega joules per $\mathrm{kg}$ ) increased $80 \%$ over this period. This increase in energy was primarily driven by groundwater pumping by farmers that constituted $61 \%$ of direct on-farm energy consumption. Shah et al. [14•] observed similar results based on a nine-country survey in sub-Saharan Africa. Small farmers using motor-pump irrigation (as compared with rainfed, gravity-flow, and manual life irrigation) reported the highest net value added per acre and per family worker. This added value is achieved through increased energy intensity that has implications for greenhouse gas (GHG) emissions (93\% of the irrigation pumps used petrol and diesel). It is reported that subsidized tariffs for agricultural water pumping in Mexico have led to increased groundwater abstraction, and irrigation constitutes over $25 \%$ of all electricity consumption in the state of Chihuahua [8*0]. Several studies have also reported that, in some regions of India, almost half of the electricity produced is used for irrigation $[1 \bullet \bullet]$.

\section{Environmental Impacts of Energy Consumption in Water End-Use}

Several papers have focused in whole or in part on the energy intensity issue motivated from an environmental impact perspective. Domestic water heating accounts for $5.5 \%$ of total GHG emissions in the UK [1••]; in Mexico [8••] agricultural pumping accounts for an estimated $3.6 \%$ of total national emissions and are equivalent to emissions from transporting the same produce to market.

Elias-Maxil et al. [36] summarize measures for reducing energy consumption related to water use in urban areas in the Netherlands. They discuss actions for reducing energy expenditure, including reducing demand, using renewable energy sources to substitute fossil fuels consumed for operating the urban water cycle, and technological options for recovering energy from hot wastewater. They report that, in modern Dutch houses, $40 \%$ of the total energy loss is through waste hot water and describe a number of case studies on reclaiming waste heat for residential space heating.

Ghimire et al. [15•] presented a life-cycle assessment (LCA) of domestic rainwater harvesting (DRWH) systems and agricultural rainwater harvesting (ARWH) systems in the Back Creek watershed in Virginia, USA, to understand the environmental implications of rainwater harvesting relative to conventional water delivery. The results found that a pumped DRWH system performed worse than municipal supply in seven of 14 impact categories that included worse impact on energy demand and global warming. However, if there is no pumping in the DRWH, it performs better than the municipal supply system. In the agricultural case, the ARWH system performed better than well water in most LCA categories, and an ARWH that required no pumping performed better than well water in all 14 LCA categories.

\section{Discussion and Conclusions}

This review of recent work on the energy intensity of water end-uses in the domestic and agricultural sectors highlights the need for continued research in this area. With increasing urbanization, changing climatic conditions, and shifting technological implementation, the energy consumption for water end-use is likely to change over time. It is important that the synergies and tradeoffs between water end-use, energy consumption, economic implications, and environmental impacts are holistically understood and carefully used in policy. Otherwise, partial solutions can have unintended effects - such as reported in Scott [8・•], where night-time subsidized power for agricultural groundwater use has driven increased pumping, reversing past gains in water and electricity conservation, or the cases where mandated rainwater harvesting has increased energy intensity in some regions in Australia [12•]. The national and regional hydro-geological and socio-ecological context should be included in designing policy interventions that ensure water and energy security while preventing resource depletion and deterioration [37]. This consideration of context is particularly important in the agricultural sector, where measures for water efficiency (such as use of pressurized systems) should also be evaluated for impacts on overall energy use and carbon emissions. 
Within the urban domestic sector, several studies underscored the significance of hot water and its importance in the overall energy intensity of water end-use. While space heating and cooling receives attention in regards to energy use in buildings, water heating also needs to be considered as an important component to be included in efforts to reduce energy consumption in buildings. Since a reduction in the energy intensity for water end-use can allow for direct cost savings for users, municipal and state governments should highlight this to incentivize synergistic water and energy conservation schemes. Work is being conducted to investigate the use of solar hot water heaters (SHWH) to reduce electricity and gas consumption for hot water [38•]; however, detailed assessments are needed that go beyond technology prescription, and include key factors of hot water demand, tank sizes, and electricity tariff levels etc., to determine choice of optimal system design [39]. Several countries have implemented policies to incentivize the installation of SHWH in residential buildings. Israel has mandated SHWH since 1980 in response to rising oil prices and has achieved an installation base of $77 \%$; Australia and China have more moderate SHWH incentive policies and have achieved $7.6 \%$ and $11 \%$ installation bases, respectively [40]. Another nascent research area is the potential for grey water in residential buildings to reduce energy consumption for hot water heating in buildings, either by harnessing the heat content of grey water using heat pumps $[41,42]$ or using the potential energy of grey water in tall buildings to power turbines [43]. While additional research is needed and results will vary based on key factors, including climate, heat pump sizing, and hot water demand profile, the energy savings for hot water heating could be as high as 17 $34 \%$ [42].

The impact on energy consumption of changing architecture in water supply systems (from centralized to an increasing degree of decentralization), as well as changing urban form (with high-density residences and high rises requiring booster pumping, etc.), are not completely known nor fully incorporated into planning. Additionally, the continued migration from rural to urban communities has implications for increased urban water demand that have comparatively higher associated energy for end-use [44]. Water reuse will also play an important role in meeting future water demands - particularly in water-scarce regions - and energy implications will need to be better understood $[45,46]$.

\section{Compliance with Ethics Guidelines}

Conflict of Interest Afreen Siddiqi and Sarah Fletcher declare that they have no conflict of interest.

Human and Animal Rights and Informed Consent This article does not contain any studies with human or animal subjects performed by any of the authors.

\section{References}

Recently published papers of particular interest have been highlighted as:

- Of importance

• Of major importance

1.• Rothausen SGSA, Conway D. Green house gas emissions from energy use in the water sector. Nat Clim Chang. 2011;1:210-9. Review of studies of GHG intensity of water sector and identifies water-end use as major energy use segment in water lifecycle.

2. US Department of Energy. The water-energy nexus: challenges and opportunities. Washington, DC: US Department of Energy; 2014.

3. Cohen R, Nelson B, Wolff G. Energy down the drain: the hidden costs of California's water supply. New York: Natural Resources Defense Council; 2004.

4. McMahon JE, Price SK. Water and energy interactions. Ann Rev Environ Res. 2011;36:163-91.

5. Perrone D, Murphy J, Hornberger GM. Gaining perspective on the water-energy nexus at the community scale. Environ Sci Technol. 2011;45:4228-34.

6.• Plappally AK, Lienhard JH. Energy requirements for water production, treatment, end use, reclamation, and disposal. Renew Sust Energ Rev. 2012;16:4818-48. Wide ranging review of studies and compilation of reported data on energy intensity of water treatment and water end use in residential and agriculture uses.

7. Siddiqi A, de Weck OL. Quantifying end-use energy intensity in the urban water cycle. J Infrastruct Syst. 2013;19:474-85. Develops an analytical framework to assess future energy demands related to urban water cycle and determines energy related to residential water end use to be comparable with desalination for the case of Masdar City in United Arab Emirates.

8.• Scott CA. Electricity for groundwater use: constraints and opportunities for adaptive response to climate change. Environ Res Lett. 2013;8, 035005. 8 pp. Examines the impact of electricity tariffs subsidies on groundwater pumping for irrigation in Mexico, and discusses threat to long-term sustainability of aquifers and increased GHG emissions.

9. Siddiqi A, Wescoat JL. Energy use in large-scale irrigated agriculture in the Punjab province of Pakistan. Water Int. 2013;38(5):57186.

10. Web of Science. Web of Science Research Areas. 2014. URL: http://images.webofknowledge.com/WOKRS57B4/help/WOS/ hp_research_areas_easca.html. Accessed Nov 2014.

11. Kenway SJ, Lant PA, Priestly A, Daniels P. The connection between water and energy in cities: a review. Water Sci Technol. 2011;63(9):1983-90.

12. Talebpour MR, Sahin O, Siems R, Stewart RA. Water and energy nexus of residential rainwater tanks at an end-use level: case of Australia. Energy Build. 2014;80:195-207. Detailed empirical study, using smart meters, of end-use energy intensity in nineteen residential systems in Queensland, Australia. The results can inform building code specifications for rainwater harvesting systems.

13. Willis RM, Stewart RA, Giurco DP, Talebpour MR, Mousavinejad A. End use water consumption in households: impacts of sociodemographic factors and efficient devices. J Clean Prod. 2013;66: 107-15. Demonstrates impact of user behavior and efficient devices on end-use energy intensity using combination of smart meter data and user surveys.

14. Shah T, Verma S, Pavelic P. Understanding smallholder irrigation in Sub-Saharan Africa: results of a sample survey from nine countries. Water Int. 2013;38(6):809-26. Nine-country survey in Sub-Saharan Africa demonstrates that motor-pump irrigation method provides 
largest net value added per acre and per family worker, for small farmers, as compared to gravity flow and manual irrigation methods.

15. Ghimire SR, Johnston JM, Ingwersen WW, Hawkins TR. Life cycle assessment of domestic and agricultural rainwater harvesting systems. Environ Sci Technol. 2014;48:4069-77. Lifecycle assessment of rainwater harvesting systems in Virginia, USA shows that minimal system designs using shortened distribution distance and no pump outperforms municipal drinking water supply in most lifecycle impact categories.

16. Abdallah AM, Rosenberg DE. Heterogeneous residential water and energy linkages and implications for conservation and management. J Water Resour Plan Manag. 2014;140:288-97. Simulation using data from 11 US cities demonstrates that wide variation in energy use across households is influenced by both technological and behavioral factors.

17. Chen Y, Li L, Jiang L, Grady C, Li X. The impact of urban water use on energy consumption and climate change: a case study of household water use in Beijing. In: Younos T, Grady CA (editors). Climate change and water resources. Springer. 2013:169-198

18. Pardo MA, Manzano J, Cabrera E, Garcia-Serra J. Energy audit of irrigation networks. Biosyst Eng. 2013;115:89-101.

19. Cabrera E, Gomez E, Cabrera E. Jr, Soriano J, Espen V. Energy assessment of pressurized water systems. J Water Resour Plan Manag. 2014. doi:10.1061/(ASCE)WR. 1943-5452.0000494.

20. Nair S, George B, Malano HM, Arora M, Nawarathna B. Waterenergy-greenhouse gas nexus of urban water systems: review of concepts, state-of-art and methods. Resour Conserv Recycl. 2014;89:1-10.

21.• Grant SB, Saphores JD, Feldman DL, Hamilton AJ, et al. Taking the "waste" out of "wastewater" for human water security and ecosystem sustainability. Science. 2012;337:681-6. A review of emerging approaches for reusing and minimizing generation of wastewater. Strategies for improving water productivity are compared and role of end user behavior is emphasized.

22. Webber ME. The nexus of energy and water in the United States. AIP Conf Proceed. 2011;1401:84.

23. Massachusetts Institute of Technology. The future of natural gas. Massachusetts: MIT Energy Initiative; 2011.

24. Sanders KT, Webber ME. Evaluating the energy consumed for water use in the United States. Environ Res Lett. 2012;7:034034.

25. Cook S, Sharma A, Chong M. Performance analysis of a communal residential rainwater system for potable supply: a case study in Brisbane, Australia. Water Resour Manag. 2013;27(14):4865-76.

26. Tjandraatmadja G, Pollard C, Sharma A, Gardner T. Dissecting rainwater pump energy use in urban households. In: Begbie DK, Wakem SL, editors. Science forum and stakeholder engagement: building linkages, collaboration and science quality. Brisbane: Urban Water Security Research Alliance; 2011. p. 35.

27. Rodriguez Diaz JA, Camacho Poyato E, Blanco Perez M. Evaluation of water and energy use in pressurized irrigation networks in Sothern Spain. J Irrig Drain Eng. 2011;137(10):644-50.

28. Klein G, Krebs M, Hall V, O Brien T, Blevins BB. California's water-energy relationship. California Energy Commission. 2005.

29. Plappally AK, Lienhard JH. Costs for water supply, treatment, end-use and reclamation. Desalination Water Treat. 2013;51 (1-3):200-32.

30. Vieira AS, Beal CD, Ghisi E, Stewart RA. Energy intensity of rainwater harvesting systems: a review. Renew Sust Energ Rev.
2014;34:225-42. Detailed review of studies on energy intensity of rainwater harvesting systems showing that theoretical studies have much lower estimates in general than empirical studies.

31. Jackson TM, Khan S, Hafeez M. A comparative analysis of water application and energy consumption at the irrigated field level. Agric Water Manag. 2010;97:1477-85.

32. Matos C, Pereira S, Amorim EV, Bentes I, Briga-Sa A. Wastewater and greywater reuse on irrigation in centralized and decentralized systems - an integrated approach on water quality, energy consumption an $\mathrm{CO}_{2}$ emissions. Sci Total Environ. 2014;493:463-71.

33. Jimenez-Bello MA, Alzamora FM, Castel JR, Intrigliolo DS. Validation of a methodology for grouping intakes of pressurized irrigation networks into sectors to minimize energy consumption. Agric Water Manag. 2011;102(1):46-53.

34. Abadia R, Rocamora C, Vera J. Energy efficiency in irrigation distribution networks II: applications. Biosyst Eng. 2012;111(4): 398-411.

35. Hafeez M, Bundschuh J, Mushtaq S. Exploring synergies and tradeoffs: energy, water, and economic implications of water reuse in rice-based irrigation systems. Appl Energy. 2014;114:889-900.

36. Elias-Maxil JA, van der Hoek JP, Hofman J, Rietveld L. Energy in the urban water cycle: actions to reduce the total expenditure of fossil fuels with emphasis on heat reclamation from urban water. Renew Sust Energy Rev. 2014;30:808-20.

37. Shah $\mathrm{T}$. Groundwater Governance and Irrigated Agriculture, Global Water Partnership Technical Committee, Background paper No. 19. 2014

38. Veeraboina P, Ratnam GY. Analysis of the opportunities and challenges of solar water heating system (SWHS) in India: estimates from the energy audit surveys and reviews. Renew Sust Energy Rev. 2012;16:668-76. Evaluation of the opportunity for solar hot water heating in India finds significant potential in industrial, commercial, and residential sectors but high cost remains a barrier to large-scale adoption.

39. Vieira AS, Beal CD, Stewart RA. Residential water heaters in Brisbane Australia: thinking beyond technology selection to enhance energy efficiency and level of service. Energy Build. 2014;82:222-36.

40. Li W, Rubin T, Onyina P. Comparing solar water heater popularization policies in China, Israel and Australia: the roles of governments in adopting green innovations. Sustain Dev. 2013;21(3):160-70.

41. Meggers F, Leibundgut $\mathrm{H}$. The potential of wastewater heat and exergy: decentralized high-temperature recovery with a heat pump. Energy Build. 2011;43(4):879-86.

42. Ni L, Lau S, Li H, Zhang T, Stansbury J, Shi J, et al. Feasibility Study of a localized residential grey water energy-recovery system. Appl Therm Eng. 2012;39:53-62.

43. Sarkar P, Sharma B, Malik U. Energy generation from grey water in high raised buildings: the case of India. Renew Energy. 2014;69: 284-9.

44. Qiu GY, Li W, Li L, Zhang Q, Yang Y. Water and energy nexus in China: current situation and future perspective in energy industry, water industry and agriculture. Fundam Renew Energy Appl. 2014;4(2): 1000138 .

45. Kajenthira A, Siddiqi A, Anadon LD. A new case for promoting wastewater reuse in Saudi Arabia: bringing energy into the water equation. J Environ Manag. 2012;102:184-92.

46. Vincent L, Michel L, Catherine C, Pauline R. The energy cost of water independence: the case of Singapore. Water Sci Technol. 2014;70(5):787-94. 